\title{
FiY101: A quick guide for newly qualified doctors
}

\author{
Authors: Adam Truelove ${ }^{\mathrm{A}}$ and Alexander ] Baldwin ${ }^{\mathrm{A}}$
}

Final-year medical students in the UK have been allowed to voluntarily apply for early provisional registration in response to the COVID-19 pandemic, allowing these foundation interim year-1 (FiY1) doctors to assist in service provision in hospitals where resources and staffing may be strained. The authors, as recently qualified foundation year-1 (FY1) doctors, use this article to draw on their own experiences, and those of their colleagues, to provide advice on key topics that may not have been covered, or not covered sufficiently, in medical education, such as prescribing, rotas, wellbeing, and useful apps and websites.

KEYWORDS: Foundation interim year 1, wellbeing, prescribing, medical apps, e-learning

DOI: 10.7861/clinmed.2020-0273

\section{Introduction}

In response to the COVID-19 pandemic, the General Medical Council (GMC) has taken the unprecedented decision to allow final-year medical students in the UK to apply for early provisional registration. ${ }^{1}$ These foundation interim year-1 (FiY1) doctors will assist the strained healthcare service until starting their UK Foundation Programme as planned in August.

If this refers to you, then firstly let us congratulate you on graduating; it is easy to forget what an enormous achievement this is and how much work it took to get to this point. As well as this, we would like to extend our thanks for commencing your foundation role early to assist all of us during this ongoing crisis, especially as you were under no obligation to do so.

\section{General advice}

The objective of this article is to draw on our own experiences as foundation doctors, and those of our colleagues, to provide advice to support you with your transition from medical student to doctor; a transition that for many, even at the best of times, feel unprepared. $^{2-4}$

$>$ Introduce yourself to the team and your patients. There are many people in the multidisciplinary team, all of whom are vital

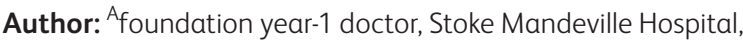
Aylesbury, UK to the care of the patient; by clearly identifying yourself, you will ensure that everyone is aware of who you are and what your responsibilities are as part of the care for your patients.

> Pay attention to the concerns of the nursing staff. Every junior doctor will have been saved by listening to and acting upon the concerns of a member of the ward team.

$>$ Do not be afraid to speak up, ask for help and escalate appropriately, especially when you are concerned about an unwell patient. Nobody will ever chastise you for escalating too early.

$>$ Know how to contact your seniors, whether this is via their phone, bleep, extension or walkie-talkie. When contacting your seniors remotely, also ensure that you clarify plans at the end of the conversation, such as repeating back salient points, so that you are all clear on the next steps needed. Tools such as SBAR (situation, background, assessment, recommendation) are useful ways to structure these conversations.

> Your trust will have a multitude of guidelines stating how to manage most common conditions. Familiarise yourself with how to find these, especially those relevant to the specialty you are starting on.

> Look after yourself. Most things, other than an acutely deteriorating patient, can wait long enough for you to take a break or handover appropriately to allow you to leave on time.

\section{Prescribing}

Prescribing can initially feel intimidating and be a source of great anxiety for newly qualified doctors. ${ }^{2,3}$ Early career doctors tend to be higher frequency prescribers, which, in turn, can be associated with higher rates of prescribing errors. ${ }^{5}$ Despite this, prescribing is a key aspect of the job of a foundation doctor, and there is little to fear as long as you remember a few key things.

> If in doubt, check the British National Formulary (BNF) app (or book).

> Refer to the local hospital guidelines over choices of drugs.

> Ask the ward pharmacist. In our experience, they are an underutilised and fantastic source of pharmacological wisdom.

$>$ When prescribing for children, consult paediatric doctors and/or nurses for advice, as doses for even common drugs can be more complex.

> Fluids are one of your most frequently prescribed medications, but it is important to always assess whether giving more fluids is appropriate and, if it is, to consider which type of fluid is most suitable to give - check the history, plan, and urea and electrolytes. 
> Do not be afraid to check why you are being asked to prescribe a particular medication, especially if it is a less common drug.

$>$ We have all, at one point, looked up the dose of paracetamol!

\section{Rotas}

Foundation rotas are often erratic and frequently changed, and this will almost definitely be true for your FiY1 rota too.

> Transcribe them onto an electronic calendar that is accessible on your smartphone (which will always be to hand), allowing you to know what your weeks ahead look like and to make plans.

$>$ Use a rota checking service (eg the one from the British Medical Association's (BMA)) to ensure that your rota is compliant with the new junior doctors' contract.

$>$ Know who your guardian of safe working hours is and how to contact them and raise concerns accordingly - we have found them to be invaluable with recent rota changes. You are still entitled to this in your contract.

$>$ Similarly, know how to exception report in your trust and do not be afraid to; many departments encourage their staff to do so as it is an easy way to flag up if your actual work has varied from your agreed work schedule and this, ultimately, facilitates accurate workforce planning. ${ }^{6}$

$>$ Check your payslip every month to ensure it is correct. You will be paid in line with the appropriate junior doctor pay scale. ${ }^{1}$ Remember that you are not due to start student loan repayments until April 2021

\section{Wellbeing}

You have a duty not just to your patients but to yourself, and it is more vital than ever to ensure you take good care of yourself, in whatever form best works for you. Plenty of advice, both general and specific to working during this pandemic, can be found online via the NHS, GMC and the BMA websites, and from your own trust. Please refer to references 7-9 for a brief introduction to the materials available; you will also find free access to wellbeing and mindfulness resources from apps such as Unmind, Headspace, Sleepio and Daylight. ${ }^{7-9}$ Reflections are also useful tools for picking apart difficult work experiences and can be used on your e-portfolio and count towards your annual review of competency progression (ARCP). ${ }^{10}$

\section{Teaching}

As a foundation doctor, there will be ample opportunity to take on more teaching responsibilities, particularly of medical students. This can initially seem like a daunting task; however it is important to remember that as recent graduates you are in a privileged position where you can acutely remember what it was like to be a medical student and thus tailor your teaching accordingly. A variety of resources focusing on the methodology of teaching can be found, both as e-learning (modules are available at www.e-Ifh.org.uk) and via face-to-face courses; there is no doubt that these are useful but practice and honesty are definitely the best ways to develop your teaching ability. Ensure you collect feedback (we prefer using online surveys, such as Google Forms, which allow easy access to the feedback at a later date) as this will not only help you improve but also keeps a log of the teaching you have done and provides evidence of this in the future.

\section{Useful apps/websites}

The latest generation of junior doctors utilises their smartphone in everyday practice. ${ }^{11}$ Here we present a non-exhaustive list of apps and websites that we, and our colleagues, have found useful during our foundation rotations; other apps and websites of a similar nature are also available.

> Induction app: a 'crowdsourced' encyclopaedia of phone extensions and bleeps (https://induction-app.com).

> MDCalc/QxMD apps: useful for rapidly calculating scores and criteria (www.mdcalc.com and https://qxmd.com/calculate-by-qxmd).

> BNF app: simple, easy to use, and so much better than the paperweight version (https://bnf.nice.org.uk).

> Microguide: a useful prescribing app used in some hospitals with local guidelines; especially important with antibiotics as they will take into account local resistance (www.microguide.eu).

> BMJ/UpToDate/Geeky Medics: good for cross-checking and further reading (www.bmj.com, www.uptodate.com/home and https://geekymedics.com).

> Free e-books for foundation docs (BMA): many associations and groups provide free e-books for foundation doctors that will save you carrying them round (https://archive.bma.org.uk/library/e-resources/e-books).

$>$ There are also COVID-specific e-learning resources that are free to access, with specific modules aimed at newly qualified doctors (https://new-learning.bmj.com/covid-19 and www.e-Ifh.org.uk/programmes/coronavirus). ${ }^{12,13}$ These can be recorded as part of your mandatory teaching log on your e-portfolio, which you will have access to as part of your FiY1 role; many learning events and core procedures can be signed off during your FiY1 year and will count towards foundation year-1 (FY1) ARCP. ${ }^{10}$

It is important to maintain patient confidentiality when using instant messaging services and some departments may prefer to use apps such as MedXnote, Siilo, Forward or Hospify to this end.

\section{Conclusion}

It is common to feel unprepared and experience stress and anxiety when starting in your new role as a foundation doctor and, although the term unprecedented gets thrown around a lot, this truly is new ground for not only you but for all of us. We want to reiterate how much we appreciate what you are doing. We hope that you will see this as the opportunity for additional learning and experience in both normal clinical and pandemic-specific duties - no other year of doctors will start their UK Foundation Programme as capable and experienced as you. Finally, we would like to leave you with an important fact: while you may feel anxious about starting, supervisors of newly qualified foundation doctors generally feel that their new trainees are well prepared for their first role and that they are quick to pick up new skills experience once they have started. ${ }^{2}$

\section{Note}

This manuscript is the first in a series that will reflect the views of foundation trainees. If you are a foundation doctor, and would like to contribute to this series, please see the Clinical Medicine website (www.rcpjournals.org/content/clinical-medicine-instructionsauthors), or contact Dr Adam Truelove via email for advice. 


\section{Acknowledgements}

Both authors would like to acknowledge their colleagues in Buckinghamshire Healthcare NHS Trust for suggestions contributing towards this manuscript.

\section{References}

1 British Medical Association. COVID-19: early provisional registration for final year students. BMA, 2020. www.bma.org.uk/adviceand-support/covid-19/your-contract/covid-19-early-provisionalregistration-for-final-year-students [Accessed 19 April 2020].

2 Kellett J, Papageorgiou A, Cavenagh P et al. The preparedness of newly qualified doctors - Views of foundation doctors and supervisors. Med Teach 2015;37:949-54.

3 Van Hamel C, Jenner LE. Prepared for practice? A national survey of UK foundation doctors and their supervisors. Med Teach 2015;37:181-8.

4 Sturman N, Tan Z, Turner J. "A steep learning curve”: junior doctor perspectives on the transition from medical student to the healthcare workplace. BMC Med Educ 2017;17:92.

5 Lewis PJ, Seston E, Tully MP. Foundation year one and year two doctors' prescribing errors: a comparison of their causes. Postgrad Med J 2018;94:634-40.

6 British Medical Association. Exception reporting for junior doctors. BMA, 2020. www.bma.org.uk/pay-and-contracts/working-hours/ work-schedule/exception-reporting-for-junior-doctors [Accessed 19 April 2020].
7 NHS. Support now. NHS. https://people.nhs.uk/help [Accessed 21 April 2020].

8 General Medical Council. Coronavirus: Your frequently asked questions. GMC. www.gmc-uk.org/ethical-guidance/ethical-hub/covid19-questions-and-answers\#Your \% 20health \% 20and \% 20wellbeing [Accessed 21 April 2020].

9 British Medical Association. COVID:19: your wellbeing. BMA, 2020 www.bma.org.uk/advice-and-support/covid-19/your-health-andwellbeing/covid19-your-wellbeing [Accessed 21 April 2020].

10 UK Foundation Programme. Impact of COVID-19 on the UK Foundation Programme 2020. UK Foundation Programme. https:// foundationprogramme.nhs.uk/covid-19/ [Accessed 23 April 2020].

11 Shenouda JEA, Davies BS, Haq I. The role of the smartphone in the transition from medical student to foundation trainee: a qualitative interview and focus group study. BMC Med Educ 2018;18:175.

12 BMJ Learning. Coronavirus disease 2019 (COVID-19). BM] Learning. https://new-learning.bmj.com/covid-19 [Accessed 22 April 2020].

13 e-Learning for Healthcare. Accessing the Coronavirus programme. e-LfH. www.e-Ifh.org.uk/programmes/coronavirus [Accessed 22 April 2020].

Address for correspondence: Dr Adam Truelove, Department of Intensive Care, Stoke Mandeville Hospital, Aylesbury HP21 8AL, UK.

Email: adam.truelove@doctors.org.uk

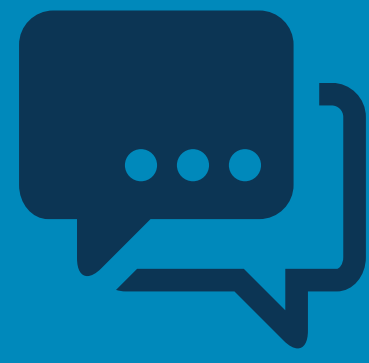

